\title{
Engineering Skills: Systematic Review in the Field of Professional Ethics
}

\section{Eloiza Kohlbeck, Amanda Melo, Gabriel Pereira dos Santos Pedrozo, Alexandre Borges Fagundes, Delcio Pereira, Fernanda Hänsch Beuren, Débora Barni de Campos*}

Centro de Educação do Planalto Norte, Departamento de Tecnologia Industrial, Universidade do Estado de Santa Catarina, Luiz Fernando Hastreiter, São Bento do Sul, SC 89283-081, Brasil

Email: *deborabarni@gmail.com

How to cite this paper: Kohlbeck, E., Melo, A., dos Santos Pedrozo, G. P., Fagundes, A. B., Pereira, D., Beuren, F. H., \& de Campos, D. B. (2021). Engineering Skills: Systematic Review in the Field of Professional Ethics. Creative Education, 12, 23352355.

https://doi.org/10.4236/ce.2021.1210177

Received: August 14, 2021

Accepted: October 19, 2021

Published: October 22, 2021

Copyright $\odot 2021$ by author(s) and Scientific Research Publishing Inc. This work is licensed under the Creative Commons Attribution International License (CC BY 4.0).

http://creativecommons.org/licenses/by/4.0/

\begin{abstract}
With the advance of globalization, adopting a holistic perspective, involving the environmental, economic and social spheres is fundamental in the profile of professionals. To ensure employability in this context, it is essential to combine technical skills and Soft Skills (noncognitive skills). In view of this, this work aims to highlight the importance of teaching Professional Ethics in the Engineering course and identify which skills are required in the exercise of this profession. For this purpose, the methodology used corresponds to a systematic review of the literature, covering bibliometric analysis and content analysis, which extends the knowledge about Soft Skills (focusing on Professional Ethics) in the teaching and exercise of Engineering. Finally, the research discusses the results through a framework, classifying the Engineer's skills under environmental, economic, and social scopes. In this way, a holistic and integrative approach is presented, which is fundamental to achieve sustainable development and to ensure the employability of this professional.
\end{abstract}

\section{Keywords}

Professional Ethics, Soft Skills, Engineering, Bibliometric Analysis, Content Analysis

\section{Introduction}

As society evolves, the labor market has become more rigorous (Verbic, Keerthisinghe, \& Chapman, 2017; Vu Anh \& Le Quoc, 2019), where workers must accompany this development in order to ensure employability (Tan Hoi \& Thi Thu Chung, 2020). In this context, it is widely recognized that education and training need new approaches to skills development (Pócsová, Bednárová, 
Bogdanovská, \& Mojžišová, 2021) that reconciles technical knowledge with Soft Skills, i.e., noncognitive skills, such as people management, customer service, and social skills (De Campos, Resende, \& Fagundes, 2020c; Pócsová et al., 2021).

The teaching of Professional Ethics acts as a contribution channel in this context (Cheruvalath, 2019), since through a pragmatic approach, it instructs professionals to solve ethical problems effectively (Zhu \& Jesiek, 2019) and with moral sensitivity (Cheruvalath, 2019). According to Liu, Yi and Wang (2020) Professional Ethics promotes awareness in order to make professionals adopt an environmental protection behavior. This awareness is fundamental to the profile of the Engineer, because this professional is involved with issues such as waste control and water or air pollution and can perform a significant role in ensuring sustainability (Cheruvalath, 2019).

The evolution of society requires a set of skills in the Engineer profile (Verbic et al., 2017), needing to reconcile technical skills with a variety of interpersonal and intrapersonal skills (De Campos et al., 2020c; Fernández-Sanz et al., 2017; Jeganathan, Khan, Kannan Raju, \& Narayanasamy, 2019; Knobbs \& Grayson, 2012; Redoli, Mompo, de la Mata, \& Doctor, 2013).

Therefore, to develop them, soft skills need to be clearly defined and articulated (Matturro, Raschetti, \& Fontan, 2019), considering a holistic context of multiculturalism (Zhu \& Jesiek, 2017) and multinationality (Fernández-Sanz et al., 2017), reconciling sustainable development (Hojem \& Lagesen, 2011; Staniškis \& Katiliute, 2016) and economic (Fischer, Pecujlija, Cosic, \& Lalic, 2019). Thus, the engineer must develop a global awareness, including environmental, social, and economic aspects (Tharakan, 2020) in all of his or her functions, inside and outside of organizations (Walińska \& Dobroszek, 2021). In view of this, the emphasis of this paper is to answer the following research questions:

RQ1: What is the importance of teaching Professional Ethics in the Engineering course?

RQ2: What are the competencies required in the exercise of Engineering in relation to the environmental, economic and social spheres?

In order to answer these questions, the aim of this study is to conduct a systematic literature review on Professional Ethics and Soft Skills, applied to teaching and exercising Engineering.

\section{Methodology}

This research has a qualitative and bibliographic character, since the method selected was a literature systematic review, which allowed to analyze the inter-relationships between Engineering, Professional Ethics and Soft Skills. The systematic reviews capture the diversity and development of literature (Alcayaga, Wiener, \& Hansen, 2019), in order to recover, synthesize and evaluate knowledge on a given subject (Møller \& Myles, 2016). 
The research was conducted in three stages (Figure 1), described in the following sections.

\subsection{Stage 1: Definition of the Scope of Research}

To identify gaps and research opportunities, a keyword combination analysis was performed through the Scopus and Web of Science databases, considered the broadest in the literature (Chadegani et al., 2013). The search for articles in these databases revealed that scientific productions on Engineering, Professional Ethics and Soft Skills generally occur individually or considering partial interrelationships (Table 1).

A research opportunity was identified by noting that there are no academic records that present a holistic view of the interaction between Engineering, Professional Ethics and Soft Skills. Thus, the research questions (RQ1 and RQ2), presented in the Introduction, were raised.

\subsection{Stage 2: Literature Search}

Once the scope and the research questions were defined, this step included a literature review using Preferred Reporting Items for Systematic Reviews and

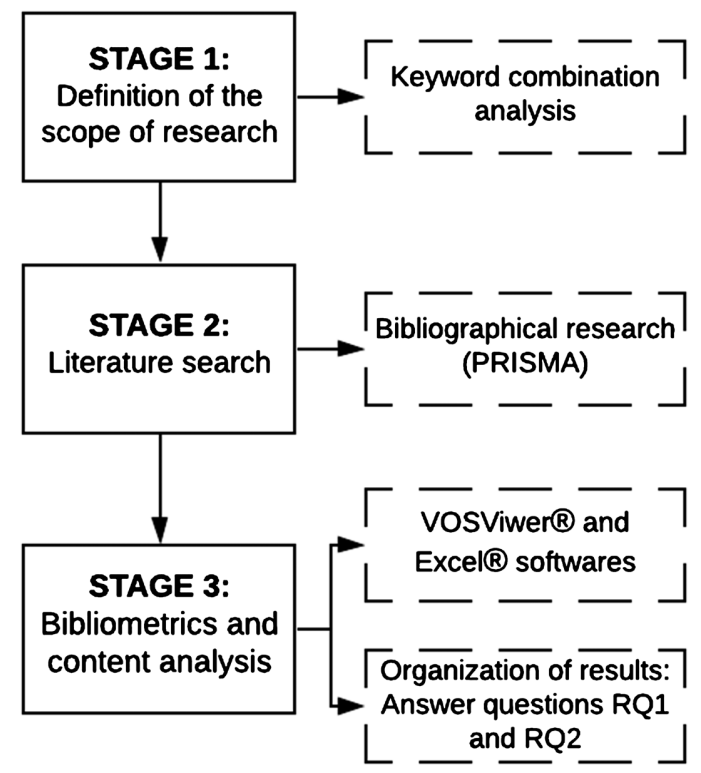

Figure 1. Stages of the research.

Table 1. Representation of interrelationships.

\begin{tabular}{ccc}
\hline \multirow{2}{*}{ KEYWORDS } & \multicolumn{2}{c}{ DATABASES } \\
\cline { 2 - 3 } & SCOPUS & WOS \\
\hline "Professional Ethics" AND "Engineering" & 15 & 25 \\
"Professional Ethics" AND "Soft Skills" & 1 & 0 \\
"Soft Skills" AND "Engineering" & 99 & 62 \\
"Professional Ethics" AND "Engineering" AND "Soft Skills" & 0 & 0 \\
\hline
\end{tabular}


Meta-Analyses-PRISMA (Figure 2). This method was used to structure the work in four stages: I-Identification of articles, II-Selection of articles, III-Eligibility and IV-Inclusion of studies (Moher, Liberati, Tetzlaff, Altman, \& PRISMA Group, 2009).

The Scopus and Web of Science databases, considered the most comprehensive (Chadegani et al., 2013), were used to identify records. The combination of keywords, presented in Table 1, was used to compose the initial sample of 1444 works.

Aiming at further refinement of the records identified in the databases, in phase II a bibliographic search was performed using filters, restricting the investigation to articles published between 2010 and 2019 and written in English. A subject filter was also employed due to the large number of documents initially

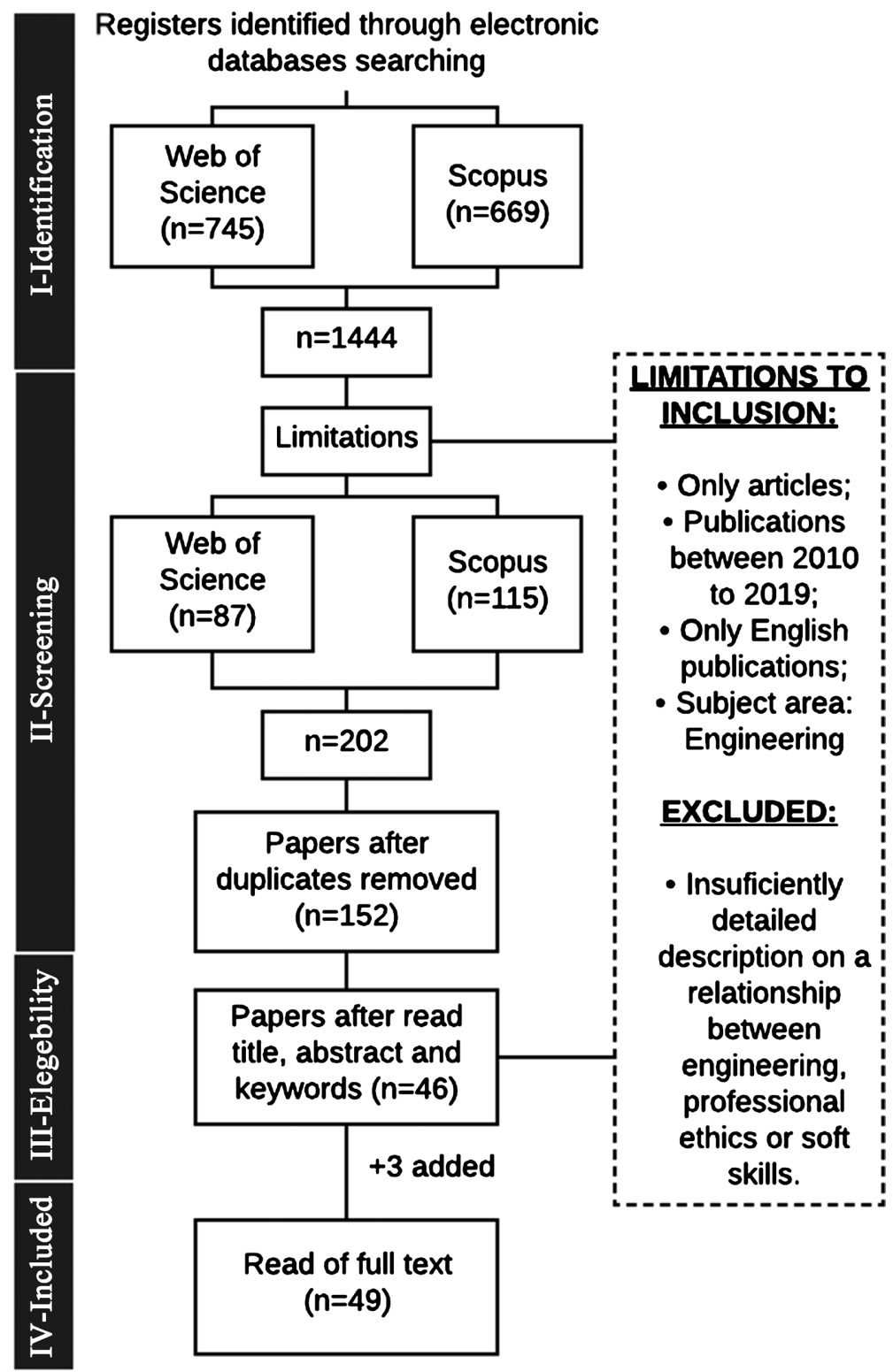

Figure 2. PRISMA application and research parameters. 
tracked, limiting the search to the Engineering area, the focus of this study. Thus, 202 articles were identified and, excluding duplicates, 152 papers were selected, which composed the bibliometric analyses.

In steps III and IV, title, abstract and keywords were analyzed in order to select the articles that were most consistent with the scope and research questions, generating greater contribution with this investigation. In stage III, 46 papers were selected to be read in full and thoroughly analyzed.

Finally, an additional selection was made (step IV), where three papers were added to the initial sample, resulting in the analysis of 49 papers, which make up the bibliographic portfolio and, composed the analysis of content of this work.

\subsection{Stage 3: Bibliometrics and Content Analysis}

This work employs an approach from two perspectives, combining bibliometric and content analysis (Braz et al., 2018). The bibliometric analysis covered 152 articles, and was included in order to create an overview of the bibliographic portfolio (van der Have \& Rubalcaba, 2016). In view of this, this step contemplated: time trend of publications, main journals, analysis of keyword clustering and geographic distribution of publications.

For this purpose, VOSviewer ${ }^{\circledR}$ and Excel $^{\circledR}$ softwares were used. According to Wong (2018), VOSviewer $^{\circledR}$ is a free tool that allows the creation of graphs to visualize bibliometric data (Wong, 2018), in order to create an easy to interpret mapping (Van Eck \& Waltman, 2010).

The VOSviewer ${ }^{\circledR}$ represents the correlation and the strength of the link between the bibliometric data through nodes and edges, so the higher the node, the higher the correlation (Van Eck \& Waltman, 2014). For the analyses using this software (analysis of keyword clustering and geographical distribution), the data obtained were exported from the Scopus scientific base, since VOSviewer ${ }^{\circledR}$ limits the use of a single database. Scopus was selected because it presented more results than the Web of Science for this research sample (Benachio, Freitas, \& Tavares, 2020).

Aiming at data objectivity, the bibliometric analyses performed in VOSview$e^{\circledR}$ require parameter filtering (Zupic \& Čater, 2015). Therefore, for the co-citation of keywords it was delimited that the results present at least seven occurrences. Of the total of 865 keywords, 15 met this requirement. For the analysis of geographical distribution of publications, the minimum limit determined was three articles per country. Of the 47 countries that make up the sample, 17 met the stipulated requirements. For reference management, the Mendeley ${ }^{\circledR}$ software was used in all phases of this research.

Through the bibliographic results and the full reading of the 49 papers that make up the final sample, this research presents the analysis of content. This stage highlights the importance of teaching Professional Ethics in the Engineering course and which skills are most valued in the exercise of Engineering, classifying them according to the environmental, economic and social (Soft Skills). 
Discussion section consolidates the results and presents a framework to synthesize the information that answers the RQ2 question.

\section{Results}

The first section of this chapter presents a descriptive analysis of the bibliometric results obtained with the 152 articles included in this bibliographical review. The next section presents the content analysis of the 49 selected papers.

\subsection{Bibliometric and Descriptive Analysis}

The increase in publications between 2010 and 2019 is shown in Figure 3. For this time trend analysis, the papers were exported from the Scopus and Web of Science databases and the duplicates for each inter-relationship were removed.

Thus, it is observed that the interrelationship between Soft Skills and Engineering is the dimension most approached in the literature (123 articles), followed by Professional Ethics and Engineering (35 articles). However, the interrelation between Professional Ethics and Soft Skills presents only one publication, by Rameli et al. (2018), in which the authors, through a case study, analyze how learning activities based on experimentation contribute to the development of Soft Skills, as Professional Ethics.

According to Figure 3, the number of publications on the approaches presented in this work has grown over the years, especially in 2019, which obtained a $90 \%$ increase in publications when compared to 2018.

This rise in the time trend curves can be justified by the academic importance that the Soft Skills research topic has received in recent years. In this context, Professional Ethics is pointed out as a Soft Skill requested in the profile of the engineer (i.e. Abdul-Rahman, Wang, \& Saimon, 2011; Bairaktarova \& Woodcock, 2015; De Campos et al., 2020a; Cheruvalath, 2019; Hojem \& Lagesen, 2011; Maria Gil-Martin, Hernandez-Montes, \& Segura-Naya, 2010; Zhu \& Jesiek, 2017).

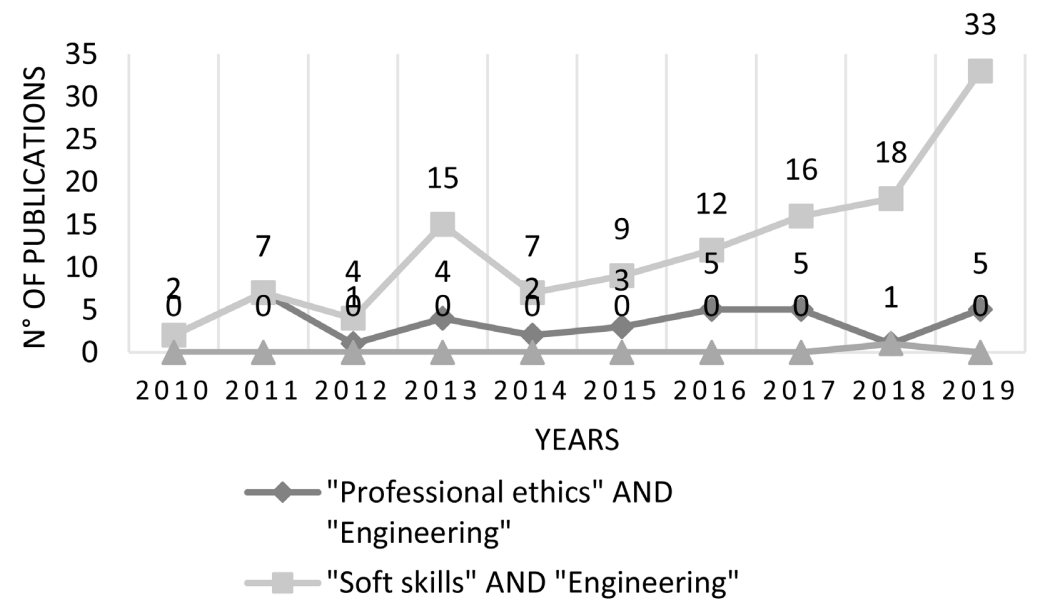

Figure 3. Temporal trend of publications. 
Considering the main journals, i.e., those with the largest number of publications (Figure 4), it can be observed that the International Journal of Engineering Education and the journal Science and Engineering Ethics together hold 30\% of publications.

Analyzing the sample of 152 articles of this stage of the research, it is observed that the papers were published in 67 different journals. Figure 4 presents the journals that presented more than three publications in the research lines worked.

In order to map the most discussed research topics in the literature, the VOSviewer $^{\circledR}$ software was used to analyze the grouping of keywords. Figure 5 highlights the formation of three clusters, creating a bibliometric network composed of 15 nodes.

Figure 5 presents the formation of the three clusters, where it can be observed that predominantly cluster 1 addresses questions about engineering practice. Cluster 2, on the other hand, points out a trend in keywords for subjects related to Engineering teaching, while Cluster 3, predominantly, addresses issues related to teaching methodologies.

Among the keywords most used are "Engineering education", with 48 occurrences, "Students", with 47, and "Education" (28 occurrences). The three

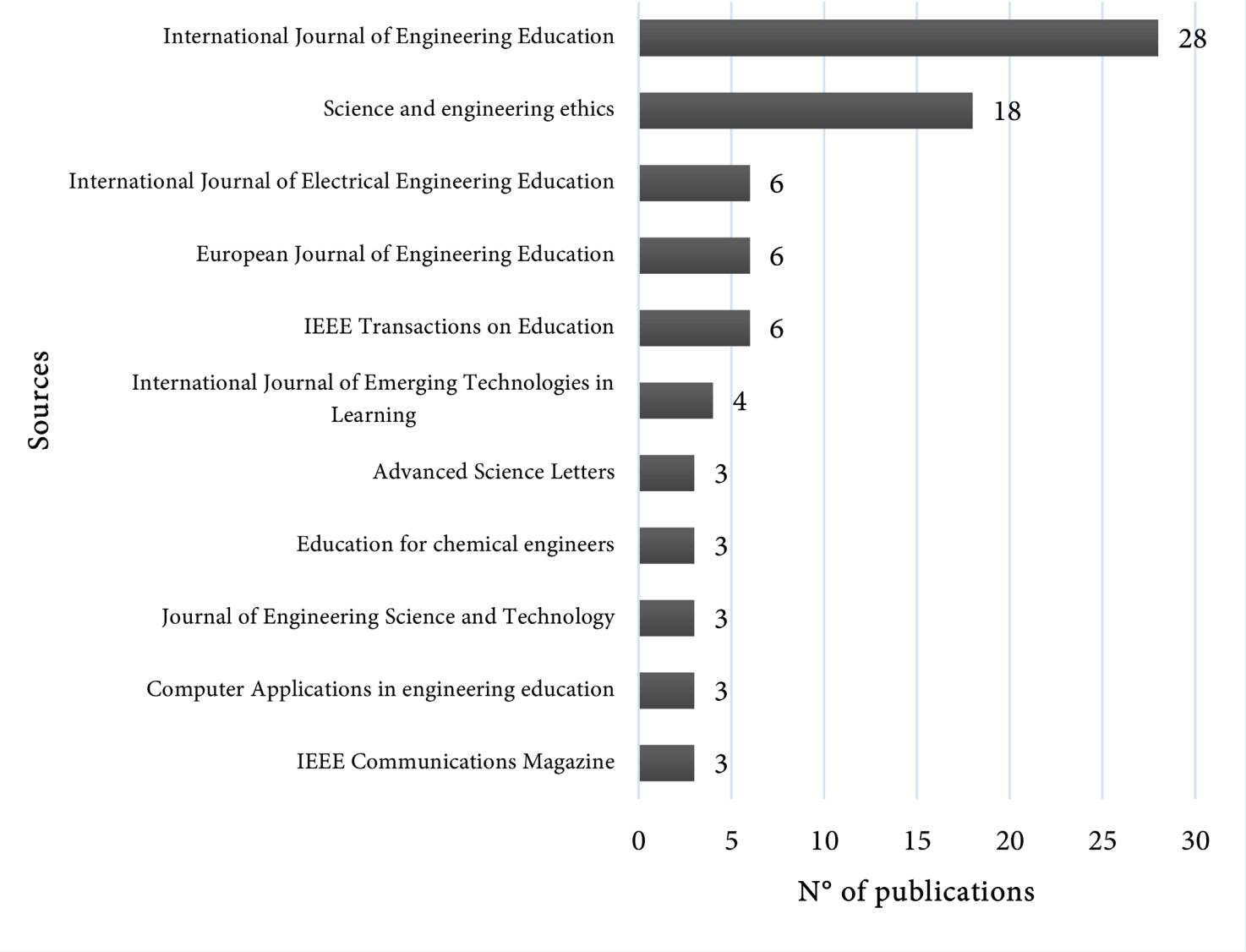

Figure 4. Main journals. 


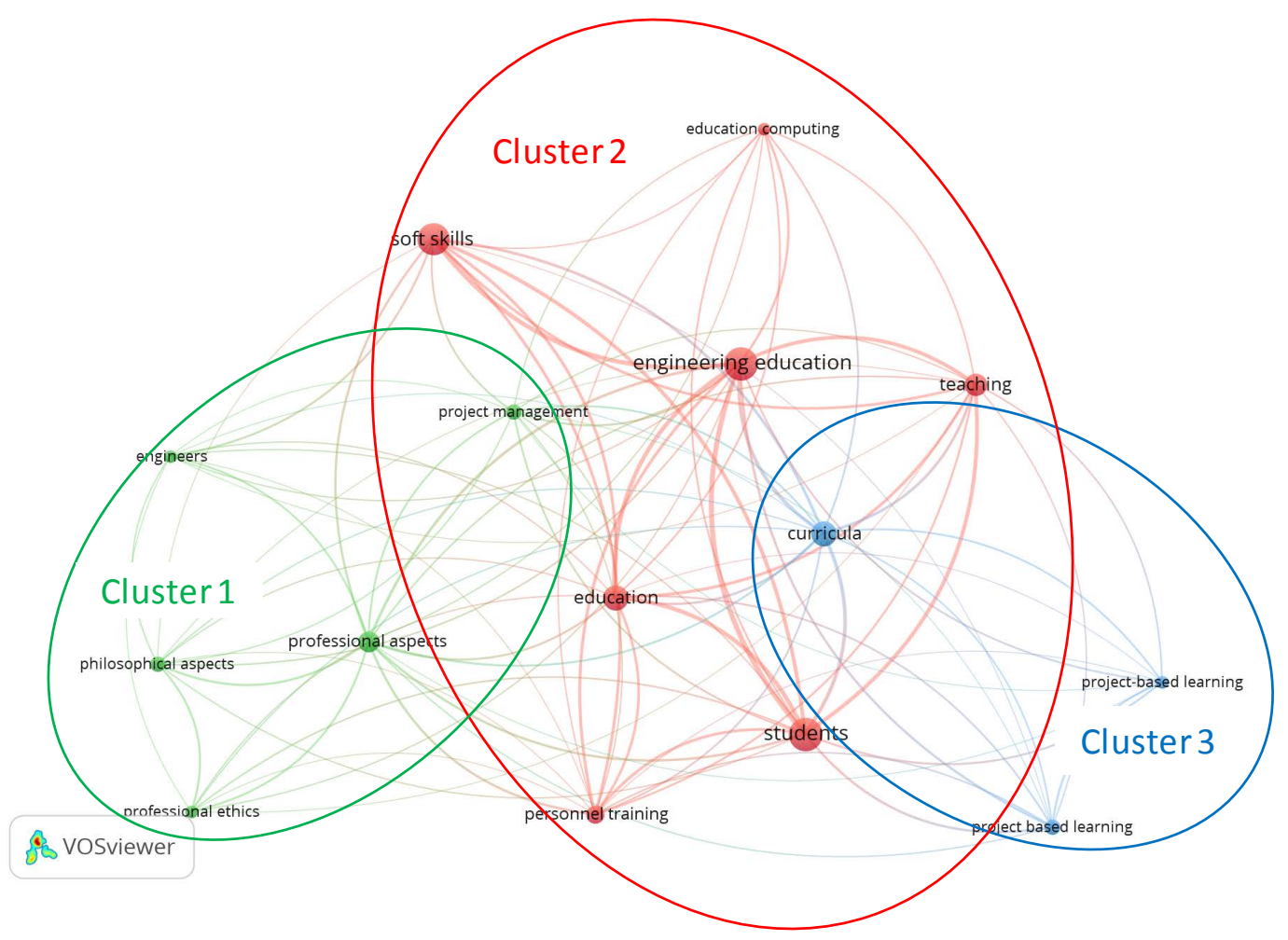

Figure 5. Analysis of keyword clustering.

most used keywords belong to cluster 2, where the works of Campos, Resende and Fagundes, published in 2020, stand out, with the publication "Fuzzy Model for Diagnosing Soft Skills in Engineering Training", where the authors propose a scientific modeling, based on fuzzy logic. Among its contributions, the model considers the perceptions of students and teachers for the development of pedagogical projects in the Engineering area.

In cluster 3, two terms with the same meaning are used: "Project based learning" and "Project-based learning", since the software does not recover expansions that keywords present.

The VOSviewer ${ }^{\circledR}$ software was also used to analyze the geographic distribution of publications (Figure 6), highlighting the countries with the largest quantity of documents and quotations, as well as a chronological analysis.

Analyzing Figure 6, it was verified that the United States and Malaysia appear as the countries with the largest amount of publications, since together they correspond to $21 \%$ of the analyzed sample.

The United States corresponds to the country with the largest number of publications, with 18 articles and 56 citations. Besides the relevance of the content of these articles, this high number of citations can be justified by the fact that its publications are older (Figure 6) in order to present a longer period for citations.

The country that presented the largest number of citations was Germany, despite having only three articles related to the analyzed sample, demonstrating the academic relevance given to the published works. 


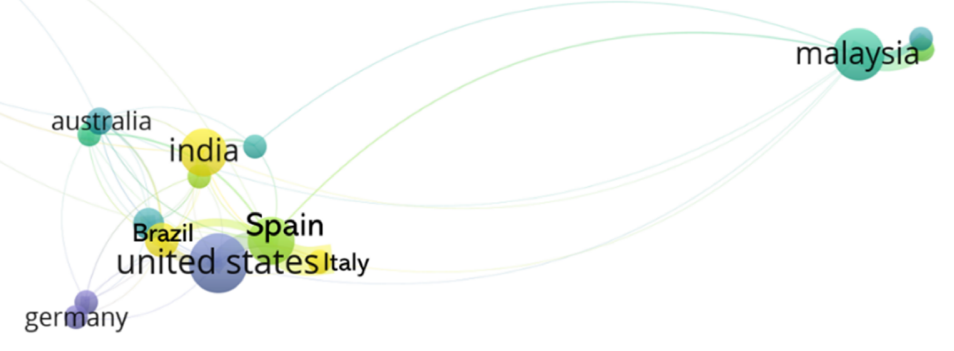

\section{VOSviewer}

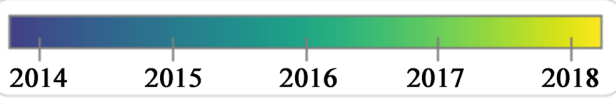

Figure 6. Geographical distribution.

\subsection{Content Analysis}

Based on the descriptive analysis and full reading of the 49 papers in the research corpus, the content analysis was carried out, which is organized as follows: first subsection answers the research question RQ1, highlighting the importance of teaching Professional Ethics in the Engineering course. Following subsection answer the RQ2 question, analyzing, respectively, which are the competencies required in the exercise of Engineering, in the environmental, economic and social spheres.

\subsubsection{Importance of Teaching Professional Ethics}

Several researchers approach the importance of teaching Professional Ethics in the Engineering course, highlighting the works of Abdul-Rahman et al. (2011), Bairaktarova and Woodcock (2015), De Campos, Resende and Fagundes (2020a, 2020b, 2020c); Cheruvalath (2019) and Zhu and Jesiek (2017).

Driven by the demand of the labor market for employees who combine technical skills and Soft Skills (De Campos et al., 2020a; Fernández-Sanz et al., 2017; Knobbs \& Grayson, 2012; Matturro et al., 2019; Redoli et al., 2013), the approach on Professional Ethics has been gaining notoriety in the literature, as verified in the bibliographical analysis.

Zhu and Jesiek (2017) conducted a literature review on the dominant themes in the current teaching of Professional Ethics in Engineering. The authors emphasize that besides the traditional approach, which simulates the practice of Ethics through theories, it is necessary to adopt a pragmatic approach in order to rethink the ethical reasoning. Through this approach, the authors emphasize the practical plausibility of decision making and problem solving based on Ethics.

The work of Abdul-Rahman et al. (2011) corroborates the results of Zhu and Jesiek (2017). Through structured interviews, with 23 project managers (41.8\%), 7 company directors (12.7\%) and 25 executive managers (45.5\%), the practice of Professional Ethics in the construction industry was analyzed. The authors ana- 
lyzed the causes of unethical conducts and, point out that the main reason that leads to these conducts in the Malaysian construction industry is the insufficient ethical education in schools.

Through the results of the structured interviews, Abdul-Rahman et al. (2011) also highlight ways to mitigate unethical conduct, where the main alternatives are to make penalties more severe and to update current legislation. Finally, the authors propose two models with disciplinary procedures to deal with ethical problems in the construction industry: one for "small" conducts, such as arriving late, and the second model for "serious" unethical conducts, such as fraud.

Cheruvalath (2019) affirms that training in Professional Ethics is a predictor of the metamoral cognitive ability of Engineering students. The results show that there was a substantial difference in metamoral cognitive skills between students who studied Professional Ethics and those who did not, and highlight that student participation in the teaching-learning process makes this education more effective.

Campos, Resende and Fagundes published three articles in 2020, presenting the results obtained in the first author's $\mathrm{PhD}$ thesis. A brief explanation of the works is presented in this research. The article "The Importance of Soft Skills for the Engineering", through a systematic literature review, gathers and presents the works about the social skills required in the profile of the Engineer, such as Professional Ethics, capable of ensuring employability and adequacy to market demands. The authors present the most relevant Soft Skills for Engineering, grouping them in six clusters: Problem Solving and Critical Thinking, Communication, Teamwork, Ethical Perspective, Emotional Intelligence and Creative Thinking.

In a complementary way, the work "Soft Skills by Engineering Employers" compares the expectations and reality of Engineering employers regarding social skills. The authors emphasize that during the elaboration of pedagogical projects, it is unusual to use scientific instruments that consider socio-emotional skills, such as Professional Ethics, for the training of Engineers. Thus, the authors emphasize that it is necessary to incorporate methodologies, actions and practices in the teaching and profession of Engineering, in order to provoke critical reflections and to make Soft Skills more present in the teaching and exercise of Engineering. Finally, the work "Fuzzy Model for Diagnosing Soft Skills in Engineering Training" provides a scientific modeling, based on fuzzy logic, to perform an evaluation and to facilitate decision making, based on multiple criteria, for the diagnosis of Soft Skills in Engineering courses.

\subsubsection{Environmental Skills}

Through literature review, the competencies required in the engineer's environmental profile (represented by the acronyms ENC1 to ENC6) were identified and are presented in Table 2.

\subsubsection{Economic Skills}

The competencies required in the engineer's profile in the economic sphere were identified and represented by the acronyms ECC1 to ECC6 (Table 3). 
Table 2. Environmental skills.

\begin{tabular}{lll}
\hline IND & ENGINEER'S SKILLS & SOURCES \\
\hline ENC1 & Environmental awareness & $\begin{array}{l}\text { (Cheruvalath, 2019; Gupta, 2015; Hojem \& Lagesen, 2011; Kist \& Brodie, 2011; Ogunsanmi, 2016; } \\
\text { Staniškis \& Katiliute, 2016; Sunthara valli \& Vishnu Priya, 2019; Verbic et al., 2017) }\end{array}$ \\
ENC2 & Waste Management & $\begin{array}{l}\text { (Cheruvalath, 2019; Staniškis \& Katiliute, 2016) } \\
\text { (Cheruvalath, 2019; Donaldson, 2017; Gupta, 2015; Hojem \& Lagesen, 2011; Kist \& Brodie, 2011; }\end{array}$ \\
ENC3 & Sustainable skills & $\begin{array}{l}\text { Monteiro, Reis, da Silva \& Souza, 2017; Ogunsanmi, 2016; Staniškis \& Katiliute, 2016; Sunthara valli \& } \\
\text { Vishnu Priya, 2019) }\end{array}$ \\
ENC4 & Avoid pollution & (Cheruvalath, 2019; Hojem \& Lagesen, 2011; Staniškis \& Katiliute, 2016) \\
ENC5 & Reduction of fossil fuels & (Verbic et al., 2017) \\
ENC6 & Renewable energy sources & (Gupta, 2015; Staniškis \& Katiliute, 2016; Verbic et al., 2017) \\
\hline
\end{tabular}

Table 3. Economic skills.

\begin{tabular}{lll}
\hline IND & ENGINEER'S SKILLS & SOURCES \\
\hline ECC1 & Planning & (Caratozzolo, Alvarez-Delgado, \& Hosseini, 2019; Fernández-Sanz, et al., 2017; Fischer et al., 2019; \\
& & Jafari-Marandi, Smith, Burch, \& Vick, 2019; Karmis, 2017; Matturro et al., 2019; Sunthara valli \& Vishnu \\
& Priya, 2019) \\
& (De Campos et al., 2020a, 2020b, 2020c; Fernández-Sanz, et al., 2017; Jafari-Marandi et al., 2019; \\
& Matturro et al., 2019; Monteiro et al., 2017; Sunthara valli \& Vishnu Priya, 2019) \\
ECC2 & Innovation & (Ballesteros-Sanchez, Ortiz-Marcos, Rodriguez-Rivero, \& Juan-Ruiz, 2017; Burnik \& Košir, 2017; De \\
& & Campos et al., 2020b; Jafari-Marandi et al., 2019; Matturro et al., 2019; Soares, Sepúlveda, Monteiro, \\
ECC3 & Negotiation & Lima, \& Dinis-Carvalho, 2013) \\
& & (De Campos et al., 2020c; Fischer et al., 2019; Gupta, 2014; Itani \& Srour, 2016; Jafari-Marandi et al., \\
& 2019; Soares et al., 2013) \\
ECC4 & Entrepreneurship & (Burnik \& Košir, 2017; Donaldson, 2017; Jafari-Marandi et al., 2019; Lurie \& Mark, 2016; Monteiro et al., \\
& & 2017; Ogunsanmi, 2016; Sunthara valli \& Vishnu Priya, 2019; Voss, 2013) \\
ECC5 & Technology skills & (Jafari-Marandi et al., 2019; Ogunsanmi, 2016; Pons, 2016) \\
& &
\end{tabular}

\subsubsection{Social Skills}

The competencies required in the engineer's profile in the social field were identified and understood as Soft Skills (Table 4). To synthesize the information in this area, a classification was made in four clusters: Social Justice (SC1 to SC4), Management with Professional Ethics (SC5 to SC10), Interpersonal Skills (SC11 to SC20) and Intrapersonal Skills (SC21 to SC36).

\section{Discussions}

Based on the results presented, this section consolidates the information from the descriptive and content analysis, where there is a synthesis of the results that answer the research questions (RQ1 and RQ2).

\subsection{Bibliographical and Descriptive Discussion}

In Figure 3, it is observed that in 2019 there was a $90 \%$ increase in publications related to the approaches worked, as compared to 2018. This highlights the academic value of the subjects under discussion in this work. 
Table 4. Social skills.

\begin{tabular}{|c|c|c|c|}
\hline CLUSTERS & IND & ENGINEER'S SKILLS & SOURCES \\
\hline \multirow[t]{4}{*}{ SOCIAL JUSTICE } & SC1 & $\begin{array}{l}\text { Gender equality in the } \\
\text { professional field/feminist ethics }\end{array}$ & (Ecklund \& Di, 2017; Zhu \& Jesiek, 2017) \\
\hline & SC2 & Multiculturalism & (De Campos et al., 2020a, 2020b; Staniškis \& Katiliute, 2016; Zhu \& Jesiek, 2019) \\
\hline & SC3 & Awareness & $\begin{array}{l}\text { (Donaldson, 2017; Knobbs \& Grayson, 2012; Maria Gil-Martin et al., 2010; } \\
\text { Matturro et al., 2019) }\end{array}$ \\
\hline & SC4 & Morality & $\begin{array}{l}\text { (De Campos et al., 2020b; Cheruvalath, 2019; Gelfand, 2016; Gupta, 2015; Maria } \\
\text { Gil-Martin et al., 2010; Miñano, Uruburu, Moreno-Romero, \& Pérez-López, 2017) }\end{array}$ \\
\hline \multirow{6}{*}{$\begin{array}{l}\text { MANAGEMENT } \\
\text { WITH } \\
\text { PROFESSIONAL } \\
\text { ETHICS }\end{array}$} & SC5 & $\begin{array}{l}\text { Formal and informal rules } \\
\text { compliance }\end{array}$ & $\begin{array}{l}\text { (Ecklund \& Di, 2017; Hojem \& Lagesen, 2011; Lurie \& Mark, 2016; Maria } \\
\text { Gil-Martin et al., 2010; Miñano et al., 2017; Ogunsanmi, 2016; Zhu \& Jesiek, 2019) }\end{array}$ \\
\hline & SC6 & Professionalism & $\begin{array}{l}\text { (Abdul-Rahman et al., 2011; Ballesteros-Sanchez et al., 2017; Burnik \& Košir, } \\
\text { 2017; De Campos et al. 2020a, 2020b, 2020c; Fischer et al., 2019; Lurie \& Mark, } \\
\text { 2016; Monteiro et al., 2017; Ogunsanmi, 2016; Trope \& Ressler, 2016; Zhu \& } \\
\text { Jesiek, 2017) }\end{array}$ \\
\hline & SC7 & Teamwork & $\begin{array}{l}\text { (Ballesteros-Sanchez et al., 2017; Burnik \& Košir, 2017; De Campos et al., 2020a, } \\
\text { 2020b, 2020c; Fernández-Sanz, et al., 2017; Fischer et al., 2019; Itani \& Srour, } \\
\text { 2016; Jafari-Marandi et al., 2019; Knobbs \& Grayson, 2012; Masoud \& Al } \\
\text { Muhtaseb, 2019; Matturro et al., 2019) }\end{array}$ \\
\hline & SC8 & Leadership & $\begin{array}{l}\text { (Ballesteros-Sanchez et al., 2017; Burnik \& Košir, 2017; De Campos, et al. 2020a, } \\
\text { 2020b, 2020c; Custovic, 2015; Fischer et al., 2019; Karmis, 2017; Knobbs \& } \\
\text { Grayson, 2012; Matturro et al., 2019; Monteiro et al., 2017; Ogunsanmi, 2016; } \\
\text { Pons, 2016; Stovall, 2011) }\end{array}$ \\
\hline & SC9 & Problem solving capability & $\begin{array}{l}\text { (Ballesteros-Sanchez et al., 2017; Burnik \& Košir, 2017; De Campos, Resende \& } \\
\text { Fagundes, 2020a, 2020b, 2020c; Gopi Krishna et al., 2019; Jafari-Marandi et al., } \\
\text { 2019; Karmis, 2017; Kist \& Brodie, 2011; Knobbs \& Grayson, 2012) }\end{array}$ \\
\hline & SC10 & Mentoring and coaching & (Custovic, 2015; Fischer et al., 2019; Matturro et al., 2019; Michaud, 2016) \\
\hline \multirow[t]{10}{*}{$\begin{array}{l}\text { INTERPERSONAL } \\
\text { SKILLS }\end{array}$} & SC11 & Empathy & $\begin{array}{l}\text { (Ballesteros-Sanchez et al., 2017; De Campos, et al., 2020b; Chand, Kumar, \& Mittal } \\
\text { 2019; Knobbs \& Grayson, 2012; Maria Gil-Martin et al., 2010; Ogunsanmi, 2016) }\end{array}$ \\
\hline & SC12 & Common sense & (De Campos, et al., 2020b; Maria Gil-Martin et al., 2010) \\
\hline & SC13 & Respect & (Michaud, 2016; Zhu \& Jesiek, 2017) \\
\hline & SC14 & Decision making ability & $\begin{array}{l}\text { (Bero \& Kuhlman, 2011; Burnik \& Košir, 2017; Itani \& Srour, 2016; Martin-Lara } \\
\text { et al., 2019; Miñano et al., 2017; Sunthara valli \& Vishnu Priya, 2019) }\end{array}$ \\
\hline & SC15 & Multidisciplinarity & $\begin{array}{l}\text { (De Campos, et al., 2020b, 2020c; Kist \& Brodie, 2011; Krueger-Ziolek et al., 2013; } \\
\text { Miñano et al., 2017; Monteiro et al., 2017; Ogunsanmi, 2016; Staniškis \& Katiliute, } \\
\text { 2016; Verbic et al., 2017; Vu Anh \& Le Quoc, 2019) }\end{array}$ \\
\hline & SC16 & Flexibility & $\begin{array}{l}\text { (Ballesteros-Sanchez et al., 2017; De Campos et al., 2020b, 2020c; Fernández-Sanz, } \\
\text { et al., 2017; Kist \& Brodie, 2011; Masoud \& Al Muhtaseb, 2019; Matturro et al., } \\
\text { 2019; Michaud, 2016) }\end{array}$ \\
\hline & SC17 & Life-long learning & $\begin{array}{l}\text { (Burnik \& Košir, 2017; Kist \& Brodie, 2011; Krueger-Ziolek et al., 2013; Sunthara } \\
\text { valli \& Vishnu Priya, 2019) }\end{array}$ \\
\hline & SC18 & Communication (oral or written) & $\begin{array}{l}\text { (Ballesteros-Sanchez et al., 2017; Burnik \& Košir, 2017; De Campos et al., 2020a, } \\
\text { 2020b, 2020c; Caratozzolo et al., 2019; Chand et al., 2019; Jafari-Marandi et al., } \\
\text { 2019; Ogunsanmi, 2016; Pons, 2016; Soares et al., 2013) }\end{array}$ \\
\hline & SC19 & $\begin{array}{l}\text { Ability to give and receive } \\
\text { criticism }\end{array}$ & (Matturro et al., 2019; Sunthara valli \& Vishnu Priya, 2019) \\
\hline & SC20 & Active listening & (De Campos et al., 2020a, 2020b; Sunthara valli \& Vishnu Priya, 2019) \\
\hline
\end{tabular}




\section{Continued}

INTRAPERSONAL SC21 Responsibility

SKILLS

SC2

SC23

SC24

SC25

SC26

SC27 Creativity

SC28

SC29

SC30

SC31

SC32

SC33

SC35

SC36
Critical thinking

Motivation

Assertiveness

Adaptability

Body language/presentation skills

Autonomy

Willingness to learn

Multitasking capability

Persistence

Application of knowledge in the work environment

Emotional intelligence/ psychological balance

Organization

Self-confidence

Initiative
(Abdul-Rahman et al., 2011; De Campos et al., 2020a, 2020b, 2020c; Custovic,

2015; Matturro et al., 2019; Michaud, 2016; Monteiro et al., 2017; Sunthara valli \& Vishnu Priya, 2019b; Verbic et al., 2017)

(De Campos et al., 2020a, 2020b; Fischer et al., 2019; Gopi Krishna et al., 2019; Maria Gil-Martin et al., 2010; Matturro et al., 2019; Ogunsanmi, 2016; Pinkus, Gloeckner, \& Fortunato, 2015)

(De Campos et al., 2020a, 2020b; Caratozzolo et al., 2019; Monteiro et al., 2017; Redoli et al., 2013; Sunthara valli \& Vishnu Priya, 2019b; Vu Anh \& Le Quoc, 2019)

(Ecklund \& Di, 2017; Knobbs \& Grayson, 2012; Matturro et al., 2019; Ogunsanmi, 2016)

(Ballesteros-Sanchez et al., 2017; Chand et al., 2016; Gopi Krishna et al., 2019; Karmis, 2017; Michaud, 2016; Ogunsanmi, 2016; Sunthara valli \& Vishnu Priya, 2019)

(Fischer et al., 2019; Krueger-Ziolek et al., 2013; Masoud \& Al Muhtaseb, 2019; Matturro et al., 2019)

(Ballesteros-Sanchez et al., 2017; De Campos et al., 2020a, 2020b, 2020c; Fernández-Sanz et al., 2017; Fischer et al., 2019; Jafari-Marandi et al., 2019; Matturro et al., 2019; Monteiro et al., 2017)

(Chand et al., 2016; Matturro et al., 2019; Soares et al., 2013)

(Jafari-Marandi et al., 2019; Matturro et al., 2019)

(Matturro et al., 2019; Sunthara valli \& Vishnu Priya, 2019)

(Martin-Lara et al., 2019; Matturro et al., 2019)

(Kist \& Brodie, 2011; Matturro et al., 2019; Sunthara valli \& Vishnu Priya, 2019)

(De Campos et al., 2020a, 2020b, 2020c; Chand et al., 2016; Fischer et al., 2019; Gopi Krishna et al., 2019; Michaud, 2016)

(Fischer et al., 2019; Ogunsanmi, 2016)

(Fernández-Sanz et al., 2017; Matturro et al., 2019)

(Chand et al., 2016; Fernández-Sanz et al., 2017; Jafari-Marandi et al., 2019; Matturro et al., 2019; Soares et al., 2013)

There has been a significant increase in the number of publications interrelated Soft Skills and Engineering, which is confirmed by the analysis of content, where several works address the need to reconcile Soft Skills with technical skills (i.e. De Campos et al., 2020a; Fernández-Sanz et al., 2017; Knobbs \& Grayson, 2012; Matturro et al., 2019; Redoli et al., 2013) and to develop them through the teaching of Professional Ethics (Abdul-Rahman et al., 2011; Cheruvalath, 2019; Maria Gil-Martin et al., 2010).

Regarding the main journals (Figure 4), it can be observed that the International Journal of Engineering Education and Science and Engineering Ethics together hold $30 \%$ of publications. This can be explained by the fact that these journals are directly related to Engineering education, addressing Professional Ethics and Soft Skills by periodically releasing special issues about these approaches. 
The analysis of keyword clustering (Figure 5) highlights the formation of three groups. Cluster 1 addresses, predominantly, issues related to Engineering practice, presenting keywords related to aspects that contribute to employability, such as Professional Ethics.

Cluster 2 mainly addresses the teaching of Engineering, reinforcing the importance and academic relevance of RQ1 of this work, which highlights the contribution of teaching Professional Ethics in the Engineering course.

On the other hand, cluster 3 addresses issues related to teaching methodologies, such as project based learning, which appeared twice in the analysis, since VOSviewer $^{\circledR}$ does not recover expansions that keywords present. Thus, the importance of using truncation elements in database searches is emphasized, in order to recover all the variations that a word can present. In addition, this cluster highlights the academic discussion about reformulations in teaching methods in order to reconcile theoretical and pragmatic approaches.

The analysis of geographical distribution of publications (Figure 6), points out an arbitrary distribution of publications, since it is present among several nations of different continents, demonstrating a wide involvement about the approaches of this work.

\subsection{Content Discussion}

\subsubsection{Answer to RQ1}

The content analysis highlighted that the literature has valued the approach on Professional Ethics in the context of teaching and exercising Engineering. However, some researchers point out that ethical education in schools is insufficient (Cheruvalath, 2019; Ecklund \& Di, 2017; Vu Anh \& Le Quoc, 2019; Zhu \& Jesiek, 2017), which emphasis the need for a pragmatic (Zhu \& Jesiek, 2017) and multidisciplinary approach (Staniškis \& Katiliute, 2016; Verbic et al., 2017).

Thus, arises the need to restructure teaching methodologies in order to mitigate unethical conduct (Abdul-Rahman et al., 2011), and to promote student participation in the teaching-learning process, making the teaching of Professional Ethics more effective (Cheruvalath, 2019; Soares et al., 2013).

The incorporation of Professional Ethics in Engineering teaching contributes to the students' ability to deal with morality in their daily behavior, assigning them responsibilities (Abdul-Rahman et al., 2011) in various fields, such as compliance with ethical principles governing sustainable (Hojem \& Lagesen, 2011; Staniškis \& Katiliute, 2016) and economic development (Fischer et al., 2019).

Thus, Professional Ethics shows its importance in providing graduates with essential skills to deal with the constant changes in industries, where new technologies and construction methods are progressively evolving (Ogunsanmi, 2016). The Industrial Revolution 4.0 sets new requirements for workers, requiring education to match this progress (Vu Anh \& Le Quoc, 2019).

The incorporation of Professional Ethics is essential to manage conflicts with moral sensibilities, facilitating decision making. This issue is fundamental for 
Engineering professionals, who face ethical impasses in their daily professional life (Cheruvalath, 2019).

\subsubsection{Answer to RQ2}

In order to facilitate understanding and summarize the information presented in the results, a framework (Figure 7) has been developed. The acronyms ENC, ECC and SC correspond to the competences of the engineer (classified in the environmental, economic and social scopes), according to the representation adopted in the section of results.

The framework highlights the academic importance that Soft Skills have been receiving, as it contributes to employability and differentiation in the market (Calero López \& Rodríguez-López, 2020; Weston, 2020). Among the social skills (Soft Skills) most cited by literature, the following stands out: Communication (oral and written), professionalism and teamwork.

Communication plays a central role among the Soft Skills requested in the engineer's profile, since its occurrence was observed in $55 \%$ of the papers that compose the bibliographic portfolio. The competencies belonging to the cluster "Management with professional ethics", professionalism and teamwork, were also widely cited in the analyzed sample, with $33 \%$ of occurrences. This highlights the importance of these skills and the appreciation of professionals who develop them, ensuring a fair and equal work environment based on ethical principles.

In the environmental field, Sustainable skills and Environmental awareness were the highest, with $18.5 \%$ and $14.8 \%$, respectively. Thus, it is observed that literature and the labor market are valuing professionals capable of reconciling economic and environmental development, acting in an eco-efficient manner in all stages of the production process.

In the economic sphere, "Technology mastery" and "Innovation" corresponded to the skills most valued by literature, since both obtained $14.8 \%$ of occurrences. Thus, professionals with the will to learn and to contribute to the development of the company are valued, through the mastery of new skills and with the

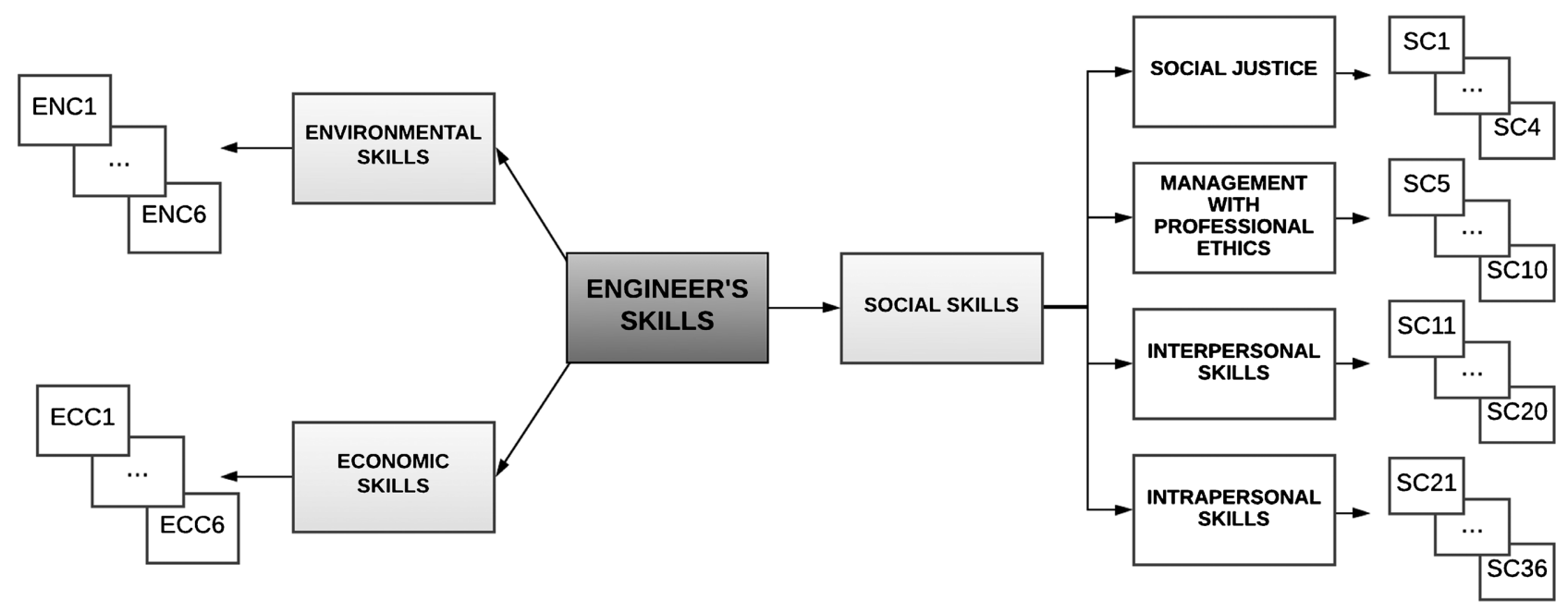

Figure 7. Framework-Engineer's skills. 
capacity to satisfy the demands of the market, contributing to the process of innovation.

Although social skills have been more valued by the literature, the framework (Figure 7) highlights that the profile of the engineer must reconcile skills in the three areas worked: environmental, economic and social. Therefore, teaching and skills development must receive a holistic perspective, capable of contributing to the sustainable development and employability of this professional.

\section{Conclusion}

This study expands the knowledge of the Soft Skills literature (focusing on Professional Ethics) in the teaching and exercise of Engineering. The research proposes a framework about the development of competencies in the profile of the engineer, classifying it in the environmental, economic and social spheres. In this way, a holistic and integrative approach is taken, fundamental to achieve sustainable development and to guarantee the employability of this professional.

The presentation and discussion of bibliographic and content results provide a source of knowledge for researchers and professionals from different areas, such as educators, interested in applying the knowledge presented, giving classes based on this research. Industry professionals can also make use of the results presented by incorporating training and capacitation in order to develop Soft Skills in their employees.

For researchers, bibliographic tracking provides a source of knowledge capable of supporting future work through the analysis of temporal trend, main journals, analysis of keyword clustering and geographical distribution of publications. In addition, it proposes an analysis of the importance of teaching Professional Ethics and identifying the skills required in the profile of the engineer, presented through a framework.

However, research limitations can be pointed out. Despite the intention to capture as many papers as possible, not all contributions in the field of Professional Ethics, Soft Skills and Engineering were identified and analyzed. There may be pertinent keywords that were not considered. In addition, the bibliometric research was limited to articles, published in English. However, omitted sources could have potential contributions to this research.

In conclusion, it can be said that the research questions have been answered and represent a future research perspective, giving continuity to the work. Therefore, it is suggested to adopt a pragmatic approach to analyze the feasibility of the proposed framework, through questionnaires or interviews, where the use of methods such as Delphi and Fuzzy Logic is recommended. In addition, a proposal to adapt the academic degree of Engineering, in order to reconcile subjects focused on the development of technical skills and Soft Skills, represents a research opportunity, given the academic relevance that the subject has been gaining. 


\section{Conflicts of Interest}

The authors declare no conflicts of interest regarding the publication of this paper.

\section{References}

Abdul-Rahman, H., Wang, C., \& Saimon, M. A. (2011). Clients' Perspectives of Professional Ethics for Civil Engineers. Journal of the South African Institution of Civil Engineering, 53, 2-6.

Alcayaga, A., Wiener, M., \& Hansen, E. G. (2019). Towards a Framework of Smart-Circular Systems: An Integrative Literature Review. Journal of Cleaner Production, 221, 622-634. https://doi.org/10.1016/j.jclepro.2019.02.085

Bairaktarova, D., \& Woodcock, A. (2015). Engineering Ethics Education: Aligning Practice and Outcomes. IEEE Communications Magazine, 53, 18-22. https://doi.org/10.1109/MCOM.2015.7321965

Ballesteros-Sanchez, L., Ortiz-Marcos, I., Rodriguez-Rivero, R., \& Juan-Ruiz, J. (2017). Project Management Training: An Integrative Approach for Strengthening the Soft Skills of Engineering Students. International Journal of Engineering Education, 33, 1912 1926.

Benachio, G. L. F., Freitas, M. do C. D., \& Tavares, S. F. (2020). Circular Economy in the Construction Industry: A Systematic Literature Review. Journal of Cleaner Production, 260, Article ID: 121046. https://doi.org/10.1016/j.jclepro.2020.121046

Bero, B., \& Kuhlman, A. (2011). Teaching Ethics to Engineers: Ethical Decision Making Parallels the Engineering Design Process. Science and Engineering Ethics, 17, 597-605. https://doi.org/10.1007/s11948-010-9213-7

Braz, A. C., De Mello, A. M., Augusto, L., Gomes, D. V., Tromboni, P., \& Nascimento, D. S. (2018). The Bullwhip Effect in Closed-Loop Supply Chains : A Systematic Literature Review. Journal of Cleaner Production, 202, 376-389. https://doi.org/10.1016/j.jclepro.2018.08.042

Burnik, U., \& Košir, A. (2017). Industrial Product Design Project: Building Up Engineering Students' Career Prospects. Journal of Engineering Design, 28, 549-567. https://doi.org/10.1080/09544828.2017.1361512

Calero López, I., \& Rodríguez-López, B. (2020). The Relevance of Transversal Competences in Vocational Education and Training: A Bibliometric Analysis. Empirical Research in Vocational Education and Training, 12, Article No. 12. https://doi.org/10.1186/s40461-020-00100-0

Caratozzolo, P., Alvarez-Delgado, A., \& Hosseini, S. (2019). Strengthening Critical Thinking in Engineering Students. International Journal on Interactive Design and Manufacturing, 13, 995-1012. https://doi.org/10.1007/s12008-019-00559-6

Chadegani, A. A., Salehi, H., Yunus, M., Farhadi, H., Fooladi, M., \& Farhadi, M. (2013). A Comparison between Two Main Academic Literature Collections : Web of Science and Scopus Databases. Asian Social Science, 9, 18-26. https://doi.org/10.5539/ass.v9n5p18

Chand, P. K., Sadasiva, A., \& Mittal, A. (2016). Emotional Intelligence and Its Relationship to Employability Skills and Employer Satisfaction with Fresh Engineering Graduates. International Journal for Quality Research, 13, 735-752.

https://doi.org/10.24874/IJQR13.03-15

Chand, P. K., Kumar, A. S., \& Mittal, A. (2019). Emotional Intelligence and Its Relationship to Employability Skills and Employer Satisfaction with Fresh Engineering Graduates. International Journal for Quality Research, 13, 735-752. 
https://doi.org/10.24874/IJQR13.03-15

Cheruvalath, R. (2019). Does Studying 'Ethics' Improve Engineering Students' Meta-Moral Cognitive Skills? Science and Engineering Ethics, 25, 583-596. https://doi.org/10.1007/s11948-017-0009-x

Custovic, E. (2015). Engineering Management: Old Story, New Demands. IEEE Engineering Management Review, 43, 21-23. https://doi.org/10.1109/EMR.2015.2430434

De Campos, D. B., Resende, L. M. M., \& Fagundes, A. B. (2020a). The Importance of Soft Skills for the Engineering. Creative Education, 11, 1504-1520. https://doi.org/10.4236/ce.2020.118109

De Campos, D. B., Resende, L. M. M., \& Fagundes, A. B. (2020b). Soft Skills by Engineering Employers. Creative Education, 11, 2133-2152. https://doi.org/10.4236/ce.2020.1110155

De Campos, D. B., Resende, L. M. M.., \& Fagundes, A. B. (2020c). Fuzzy Model for Diagnosing Soft Skills in Engineering Training. Scientific Research Publishing, 11, 2672 2721. https://doi.org/10.4236/ce.2020.1112198

Donaldson, W. (2017). In Praise of the "Ologies": A Discussion of and Framework for Using Soft Skills to Sense and Influence Emergent Behaviors in Sociotechnical Systems. Systems Engineering, 20, 467-478. https://doi.org/10.1002/sys.21408

Ecklund, E. H., \& Di, D. (2017). A Gendered Approach to Science Ethics for US and UK Physicists. Science and Engineering Ethics, 23, 183-201.

https://doi.org/10.1007/s11948-016-9751-8

Fernández-Sanz, L., Villalba, M. T., Medina, J. A., \& Misra, S. (2017). A Study on the Key Soft Skills for Successful Participation of Students in Multinational Engineering Education. International Journal of Engineering Education, 33, 2061-2070.

https://www.scopus.com/inward/record.uri?eid=2-s2.0-85037722558\&partnerID=40\&

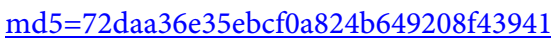

Fischer, J, Pecujlija, M., Cosic, D., \& Lalic, B. (2019). Engineering Manager: Constitutive Elements of This Profession. Engineering Studies, 11, 65-76. https://doi.org/10.1080/19378629.2019.1567522

Gelfand, S. D. (2016). Using Insights from Applied Moral Psychology to Promote Ethical Behavior among Engineering Students and Professional Engineers. Science and Engineering Ethics, 22, 1513-1534. https://doi.org/10.1007/s11948-015-9721-6

Gopi Krishna, A. K., Suneetha Reddy, K., Chitra, V. B., \& Yadav, S. (2019). Assessment of Soft Skills among Engineering Students-An Analytical Study. International Journal of Recent Technology and Engineering, 7, 91-94.

Gupta, A. (2015). Foundations for Value Education in Engineering: The Indian Experience. Science and Engineering Ethics, 21, 479-504. https://doi.org/10.1007/s11948-014-9537-9

Hojem, T. S. M., \& Lagesen, V. A. (2011). Doing Environmental Concerns in Consulting Engineering. Engineering Studies, 3, 123-143. https://doi.org/10.1080/19378629.2011.585161

Itani, M., \& Srour, I. (2016). Engineering Students' Perceptions of Soft Skills, Industry Expectations, and Career Aspirations. Journal of Professional Issues in Engineering Education and Practice, 142, Article ID: 04015005. https://doi.org/10.1061/(ASCE)EI.1943-5541.0000247

Jafari-Marandi, R, Smith, B. K., Burch, V. R. F., \& Vick, S. C. (2019). Engineering Soft Skills vs. Engineering Entrepreneurial Skills. International Journal of Engineering Education, 35, 988-998. 
https://www.scopus.com/inward/record.uri?eid=2-s2.0-85073657817\&partnerID=40\& md5=0307f4d5c19a90b1820907754a751f2a

Jeganathan, L., Khan, A. N., Kannan Raju, J., \& Narayanasamy, S. (2019). On a Frame Work of Curriculum for Engineering Education 4.0. 2018 World Engineering Education Forum-Global Engineering Deans Council (WEEF-GEDC 2018), Albuquerque, 12-16 November 2018, 1-6. https://doi.org/10.1109/WEEF-GEDC.2018.8629629

Karmis, O. (2017). A Story of a Young Professional. IEEE Engineering Management Review, 45, 32-34. https://doi.org/10.1109/EMR.2017.2734326

Kist, A. A., \& Brodie, L. (2011). Mapping Learning Outcomes and Assignment Tasks for SPIDER Activities. International Journal of Emerging Technologies in Learning, 6, 2532. https://doi.org/10.3991/ijet.v6iS2.1649

Knobbs, C. G., \& Grayson, D. J. (2012). An Approach to Developing Independent Learning and Non-Technical Skills amongst Final Year Mining Engineering Students. European Journal of Engineering Education, 37, 307-320. https://doi.org/10.1080/03043797.2012.684673

Krueger-Ziolek, S., Zhao, Z., \& Moeller, K. (2013). Involving Industry in Medical Engineering Education. Biomedical Engineering-Biomedizinische Technik, 58, Article ID: 000010151520134418. https://doi.org/10.1515/bmt-2013-4418

Liu, J., Yi, Y., \& Wang, X. (2020). Exploring Factors Influencing Construction Waste Reduction: A Structural Equation Modeling Approach. Journal of Cleaner Production, 276, Article ID: 123185. https://doi.org/10.1016/j.jclepro.2020.123185

Lurie, Y., \& Mark, S. (2016). Professional Ethics of Software Engineers: An Ethical Framework. Science and Engineering Ethics, 22, 417-434.

https://doi.org/10.1007/s11948-015-9665-X

Maria Gil-Martin, L., Hernandez-Montes, E., \& Segura-Naya, A. (2010). A New Experience: The Course of Ethics in Engineering in the Department of Civil Engineering, University of Granada. Science and Engineering Ethics, 16, 409-413.

https://doi.org/10.1007/s11948-009-9156-Z

Martin-Lara, M. A., Ianez-Rodriguez, I., \& Luzon, G. (2019). Improving the Internship Experience in the Master of Chemical Engineering at the University of Granada. Education for Chemical Engineers, 26, 97-106. https://doi.org/10.1016/j.ece.2018.07.003

Masoud, M. I., \& Al Muhtaseb, A. H. (2019). Improving Engineering Students' Writing/ Presentation Skills Using Laboratory/Mini-Project Report. International Journal of Electrical Engineering \& Education. https://doi.org/10.1177/0020720919833051

Matturro, G., Raschetti, F., \& Fontan, C. (2019). A Systematic Mapping Study on Soft Skills in Software Engineering. Journal of Universal Computer Science, 25, 16-41.

https://doi.org/10.3217/jucs-025-01-0016

Michaud, S. (2016). Feature: As HTM Evolves, Soft Skills Become More Important. Biomedical Instrumentation and Technology, 53, 438-442. https://doi.org/10.2345/0899-8205-53.6.438

Miñano, R., Uruburu, Á., Moreno-Romero, A., \& Pérez-López, D. (2017). Strategies for Teaching Professional Ethics to IT Engineering Degree Students and Evaluating the Result. Science and Engineering Ethics, 23, 263-286.

https://doi.org/10.1007/s11948-015-9746-x

Moher, D., Liberati, A., Tetzlaff, J., Altman, D. G., \& PRISMA Group (2009). Preferred Reporting Items for Systematic Reviews and Meta-Analyses: The PRISMA Statement (Reprinted from Annals of Internal Medicine). Physical Therapy, 89, 873-880.

https://doi.org/10.1093/ptj/89.9.873 
Møller, A. M., \& Myles, P. S. (2016). What Makes a Good Systematic Review and Meta-Analysis? British Journal of Anaesthesia, 117, 428-430. https://doi.org/10.1093/bja/aew264

Monteiro, S. B. S., Reis, A. C. B., da Silva, J. M., \& Souza, J. C. F. (2017). A Project-Based Learning Curricular Approach in a Production Engineering Program. Production, 27, Article ID: e20162261. https://doi.org/10.1590/0103-6513.226116

Ogunsanmi, O. E. (2016). Determining the Essential Skill Requirements for Construction Managers' Practice in Nigeria. International Journal of Construction Supply Chain Management, 6, 48-63. https://doi.org/10.14424/ijcscm602016-48-63

Pinkus, R. L., Gloeckner, C., \& Fortunato, A. (2015). The Role of Professional Knowledge in Case-Based Reasoning in Practical Ethics. Science and Engineering Ethics, 21, 767787. https://doi.org/10.1007/s11948-015-9645-1

Pócsová, J., Bednárová, D., Bogdanovská, G., \& Mojžišová, A. (2021). Review Paper on the Future of the Food Sector through Education, Capacity Building, Knowledge Translation and Open Innovation. Current Opinion in Food Science, 38, 162-167. https://doi.org/10.1016/j.cofs.2020.11.009

Pons, D. (2016). Relative Importance of Professional Practice and Engineering Management Competencies. European Journal of Engineering Education, 41, 530-547. https://doi.org/10.1080/03043797.2015.1095164

Rameli, M. R. M., Bunyamin, M. A. H., Siang, T. J., Hassan, Z., Mokhtar, M., Ahmad, J., \& Jambari, H. (2018). Item Analysis on the Effects of Study Visit pRogramme in Cultivating Students' Soft Skills: A Case Study. International Journal of Engineering and Technology (UAE), 7, 117-120. https://doi.org/10.14419/ijet.v7i2.10.10968

Redoli, J., Mompo, R., de la Mata, D., \& Doctor, M. (2013). DLP: A Tool to Develop Technical and Soft Skills in Engineering. Computer Applications in Engineering Education, 21, E51-E61. https://doi.org/10.1002/cae.20572

Soares, F. O., Sepúlveda, M. J., Monteiro, S., Lima, R. M., \& Dinis-Carvalho, J. (2013). An Integrated Project of Entrepreneurship and Innovation in Engineering Education. $\mathrm{Me}$ chatronics, 23, 987-996. https://doi.org/10.1016/j.mechatronics.2012.08.005

Staniškis, J. K., \& Katiliute, E. (2016). Complex Evaluation of Sustainability in Engineering Education: Case \& Analysis. Journal of Cleaner Production, 120, 13-20. https://doi.org/10.1016/j.jclepro.2015.09.086

Stovall, P. (2011). Professional Virtue and Professional Self-Awareness: A Case Study in Engineering Ethics. Science and Engineering Ethics, 17, 109-132.

https://doi.org/10.1007/s11948-009-9182-x

Sunthara valli, K., \& Vishnu Priya, N. S. (2019). Sustainable Employability Skills for Civil and Other Engineering Professionals in the Global Market. International Journal of Civil Engineering and Technology, 10, 1074-1080.

https://www.scopus.com/inward/record.uri?eid=2-s2.0-85060845341\&partnerID=40\& $\underline{\text { md5=30bee66a0afe80ab59d9cfe5f8b1ecb4 }}$

Tan Hoi, H., \& Thi Thu Chung, K. (2020). Developing Soft Skills for Students via Experiential Learning at Universities in Ho Chi Minh City. 2020 The 4th International Conference on Digital Technology in Education, Busan, 15-17 September 2020, 67-70. https://doi.org/10.1145/3429630.3429640

Tharakan, J. (2020). Disrupting Engineering Education: Beyond Peace Engineering to Educating Engineers for Justice. Procedia Computer Science, 172, 765-769. https://doi.org/10.1016/j.procs.2020.05.109

Trope, R. L., \& Ressler, E. K. (2016). Mettle Fatigue: VW’s Single-Point-of-Failure Ethics. IEEE Security and Privacy, 14, 12-30. https://doi.org/10.1109/MSP.2016.6 
van der Have, R. P., \& Rubalcaba, L. (2016). Social Innovation Research: An Emerging Area of Innovation Studies? Research Policy, 45, 1923-1935.

https://doi.org/10.1016/j.respol.2016.06.010

Van Eck, N, J., \& Waltman, L. (2014). Visualizing Bibliometric Networks. In Y. Ding, R. Rousseau, \& D. Wolfram (Eds.), Measuring scholarly impact: Methods (pp. 285-320). Springer.

Van Eck, N. J., \& Waltman, L. (2010). Software Survey: VOSviewer, a Computer Program for Bibliometric Mapping. Scientometrics, 84, 523-538. https://doi.org/10.1007/s11192-009-0146-3

Verbic, G., Keerthisinghe, C., \& Chapman, A. C. (2017). A Project-Based Cooperative Approach to Teaching Sustainable Energy Systems. IEEE Transactions on Education, 60, 221-228. https://doi.org/10.1109/TE.2016.2639444

Voss, G. (2013). Gaming, Texting, Learning? Teaching Engineering Ethics through Students' Lived Experiences with Technology. Science and Engineering Ethics, 19, 13751393. https://doi.org/10.1007/s11948-012-9368-5

Vu Anh, T. L., \& Le Quoc, T. (2019). Development Orientation for Higher Education Training Programme of Mechanical Engineering in Industrial Revolution 4.0: A Perspective in Vietnam. Journal of Mechanical Engineering Research and Developments, 42, 71-73.

Walińska, E., \& Dobroszek, J. (2021). The Functional Controller for Sustainable and Value Chain Management: Fashion or Need? A Sample of Job Advertisements in the Covid-19 Period. Sustainability, 13, Article No. 1739.

https://doi.org/10.3390/su13137139

Weston, D. (2020). The Value of 'Soft Skills' in Popular Music Education in Nurturing Musical Livelihoods. Music Education Research, 22, 527-540. https://doi.org/10.1080/14613808.2020.1841132

Wong, D. (2018). VOSviewer. Technical Services Quarterly, 35, 219-220. https://doi.org/10.1080/07317131.2018.1425352

Zhu, Q., \& Jesiek, B. K. (2017). A Pragmatic Approach to Ethical Decision-Making in Engineering Practice: Characteristics, Evaluation Criteria, and Implications for Instruction and Assessment. Science and Engineering Ethics, 23, 663-679. https://doi.org/10.1007/s11948-016-9826-6

Zhu, Q., \& Jesiek, B. K. (2019). Practicing Engineering Ethics in Global Context: A Comparative Study of Expert and Novice Approaches to Cross-Cultural Ethical Situations. Science and Engineering Ethics, 26, 2097-2120.

https://doi.org/10.1007/s11948-019-00154-8

Zupic, I., \& Čater, T. (2015). Bibliometric Methods in Management and Organization. Organizational Research Methods, 18, 429-472.

https://doi.org/10.1177/1094428114562629 